\title{
Numerical modeling of the 1964 Alaska tsunami in western Passage Canal and Whittier, Alaska
}

\author{
D. J. Nicolsky, E. N. Suleimani, and R. A. Hansen \\ Geophysical Institute, University of Alaska, Fairbanks, AK 99775, USA \\ Received: 30 September 2010 - Accepted: 4 November 2010 - Published: 3 December 2010
}

\begin{abstract}
A numerical model of the wave dynamics in Passage Canal, Alaska during the $M_{\mathrm{w}} 9.2$ megathrust earthquake is presented. During the earthquake, several types of waves were identified at the city of Whittier, located at the head of Passage Canal. The first wave is thought to have been a seiche, while the other two waves were probably triggered by submarine landslides. We model the seiche wave, landslide-generated tsunami, and tectonic tsunami in Passage Canal and compute inundation by each type of wave during the 1964 event. Modeled results are compared with eyewitness reports and an observed inundation line. Results of the numerical experiments let us identify where the submarine landslides might have occurred during the 1964 event. We identify regions at the head and along the northern shore of Passage Canal, where landslides triggered a wave that caused most of the damage in Whittier. An explanation of the fact that the 1964 tectonic tsunami in Whittier was unnoticed is presented as well. The simulated inundation by the seiche, landslide-generated tsunami, and tectonic tsunami can help to mitigate tsunami hazards and prepare Whittier for a potential tsunami.
\end{abstract}

\section{Introduction}

On 27 March 1964, the Prince William Sound area of Alaska was struck by the $M_{\mathrm{w}} 9.2$ megathrust earthquake with a rupture area shown in Fig. 1 (Plafker, 1965). This earthquake generated the most destructive tsunami in Alaska history and, farther south, impacted the west coast of the United States and Canada. In addition to the major tectonic

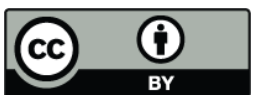

Correspondence to: D. J. Nicolsky

(djnicolsky@alaska.edu) tsunami, caused by ocean floor displacement, local tsunamis were generated by landslides in coastal Alaska (Wilson and Tørum, 1968). The port of Whittier was affected by the combined effects of locally-generated waves and the tectonic tsunami.

The port was built in 1942-1943 to provide an all-weather terminal for the Alaska Railroad and to safeguard supplies and equipment from tidewater. The locations of the railroad depot, local airport, and harbor are shown in Fig. 2. At the time of earthquake, seventy people lived in Whittier, thirteen of whom perished during the tsunami (Kachadoorian, 1965). The loss of a major port facility after the earthquake impeded supply distribution to other earthquake-affected areas such as Anchorage and Fairbanks. Relative to its population and size, Whittier sustained the heaviest damage of all Alaska communities during the earthquake. Because the tsunami was responsible for most of the damage in Passage Canal, a detailed understanding of the 1964 tsunami in Whittier must be achieved for comprehensive inundation mapping and for development of tsunami evacuation maps of Whittier. The work presented in this paper is a part of the effort to improve tsunami hazard assessment and mitigation in Whittier, Alaska with scientifically solid and tested methodology.

A previous investigation and analysis of the 1964 tsunami in Whittier was completed by Kachadoorian (1965) and Wilson and Tørum (1968). Based on eyewitness reports and observations, the authors tried to reconstruct the sequence of events in Passage Canal during the disaster and classified each observed wave by its nature. Two types of waves were identified: a seiche wave and a landslide-generated wave. Wilson and Tørum (1968) considered a resonance trinodal seiche caused by an inertial effect of the water as Passage Canal was suddenly pushed against it. Although this hypothesis is plausible, the lateral land displacement

Published by Copernicus Publications on behalf of the European Geosciences Union. 


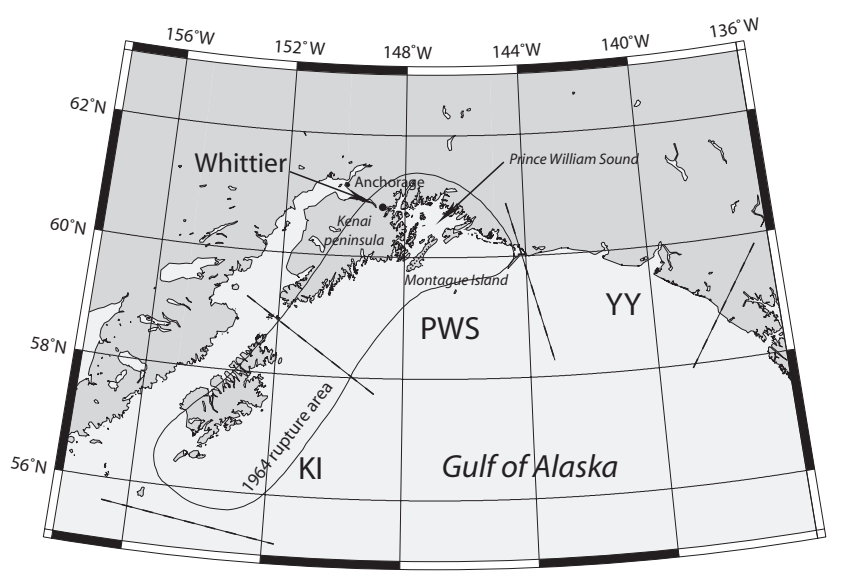

Fig. 1. Map of southcentral Alaska with rupture zone of the 1964 Great Alaska Earthquake and segments of the Alaska-Aleutian megathrust: the Prince William Sound (PWS), Kodiak Island (KI) and Yakataga-Yakutat (YY) segments.

generating this seiche needs rather complicated dynamics matching particular resonance frequencies (Wilson and Tørum, 1968). Shortly after the earthquake, Kachadoorian (1965) tried to localize submarine slope failures by exploiting pre- and post-earthquake bathymetry profiles and presented a conceptual understanding of the water dynamics caused by a submarine landslide. However, the presented explanation of the secondary wave - that it was generated when a landslide came to rest in the middle of Passage Canal - is arguable because of the assumed vertical water velocity. Finally, previous investigators concluded that an obstacle to the understanding of the observed sequence of waves was that local residents did not notice a tectonic tsunami in Passage Canal. We hypothesize that the tectonic tsunami wave was not noticed because its maximum height was within the tidal range of Whittier.

The previous researchers could qualitatively identify the nature of observed waves, but could not quantitatively compare a simulated runup to collected observations. In this article, we present a numerical modeling of the seiche and the landslide-generated and tectonic waves in Passage Canal during the 1964 event and compare our modeling results with an observed inundation line and local runup values.

The structure of this article is as follows. Based on eyewitness repots and interpretations by Kachadoorian (1965), in Sect. 2, we describe a sequence of tsunami waves and their local runup values. We state a height of each observed wave, time intervals between the waves and the nature of each observed wave. In Sect. 3, we characterize various tsunami-related hazards in Whittier. We describe sources of the submarine landslides during the 1964 event by specifying the location and volume of slides. We additionally present two models of the coseismic displacement of the 1964 earthquake, and then highlight

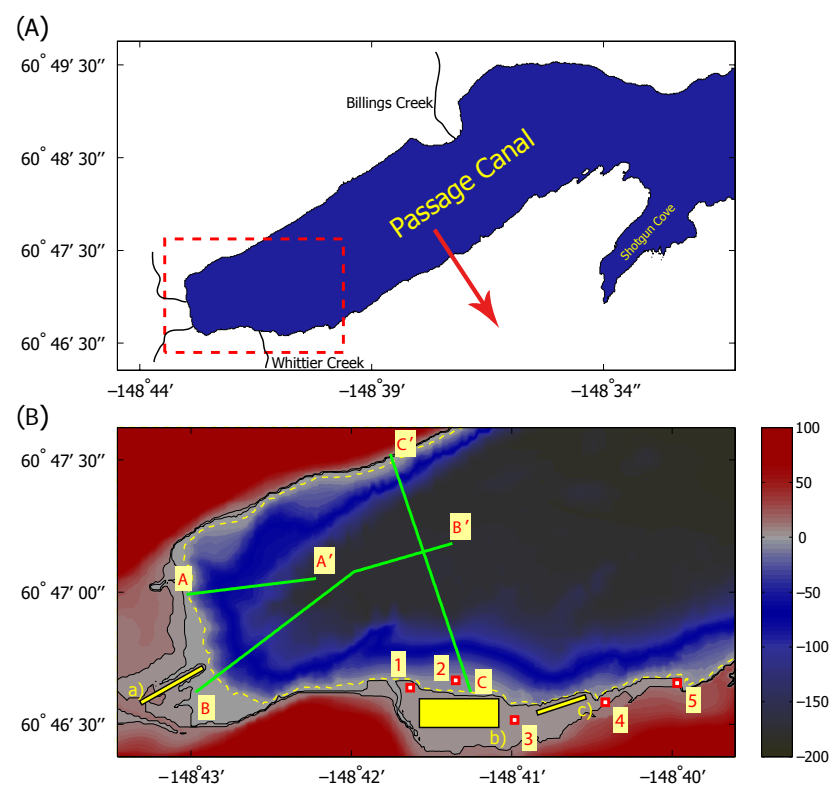

Fig. 2. (A) A drawing of the Passage Canal coastline and locations of major glacial creeks flowing into the canal. The city of Whittier is located on the southern coast of Passage Canal within an area outlined by a red rectangle. The red arrow shows a direction of the $8.2 \mathrm{~m}$ land displacement during the 1964 earthquake (Kachadoorian, 1965). (B) Digitally edited 15-m resolution DEM of the region shown within the red rectangle. The elevation is in meters above the pre-earthquake MLLW level. The dashed yellow line represent the shoreline just before the earthquake. Two black contour lines mark 5 and $10 \mathrm{~m}$ elevations above the MLLW level. The present day wave breaker and cruise ship terminal are removed from the DEM to model the 1964 bathymetry and topography. The green lines show locations of along which the bathymetry was measured before and after the 1964 earthquake (Plate 3, Kachadoorian, 1965). Yellow rectangles marked by letters a), b) and c) show locations of the airport, harbor facilities, and the railroad depot, respectively. Red-yellow rectangles, marked by numbers $1-5$, show locations at which the modeled wave height is compared to eyewitness observations.

distinctions and similarities between them. Section 4 deals with a brief description of numerical models utilized to simulate the seiche wave, landslide-generated tsunami, and the tectonic tsunami as well. In the same section, we provide details on development of a digital elevation model of the bathymetry and topography in Passage Canal. Results of the numerical modeling and their comparison to eyewitness observations are given in Sect. 5. In Sect. 6, we consider limitations of the numerical modeling, and then in Sect. 7 we discuss how the results presented in this article can help to mitigate the tsunami hazard in Whittier. Finally, in Sect. 8, we state the conclusions of this study. 


\section{Tsunami waves in Passage Canal, on 27 March 1964}

The city of Whittier was founded on a shore of Passage Canal - a steep-walled U-shaped fjord carved by glaciers. The canal is about $100 \mathrm{~m}$ deep at $150 \mathrm{~m}$ from shore at its western part and is approximately $200 \mathrm{~m}$ deep within $500 \mathrm{~m}$ of its northern shore. The maximum depth of the canal is more than $250 \mathrm{~m}$. The harbor and port facilities lie on a fan-shaped delta formed by Whittier Creek at the southern shore of Passage Canal. A digital elevation model (DEM) of Passage Canal and major creeks flowing into the ocean is shown in Fig. 2.

The $M_{\mathrm{w}} 9.2$ Alaska earthquake of 27 March 1964 at Whittier was characterized by a strong ground motion generally in east-west direction (Kachadoorian, 1965). The seismic motion accelerated to its maximum intensity in about one-half minute, maintained its strength for one minute and a half, and then gradually subsided. The post-earthquake studies by United States Geological Survey determined that the land subsided in Whittier by $1.6 \mathrm{~m}$, and the land shifted laterally by about $8.2 \mathrm{~m}$ almost transverse to Passage Canal in a southeast direction.

Whittier, unlike many coastal communities damaged by the 1964 earthquake, has a record of tsunami waves on a marigram, but the data is limited. The sequence of waves in Passage Canal was reconstructed from eyewitnesses observations. For these reasons, there are inherited uncertainties in estimates of wave time arrivals and wave heights. At least three waves were observed during the earthquake or immediately after it. A minute after the shaking began, a glassy wave rose to the altitude of $7.6 \mathrm{~m}$ a.s.l. which at that time was $0.3 \mathrm{~m}$ above the Mean Lower Low Water (MLLW) level. The wave rose rapidly and immediately receded. Then, 60 to $90 \mathrm{~s}$ later, a muddy 12.2-m-high breaking wave inundated the port facilities and ran-up to an elevation of $10.7 \mathrm{~m}$, approximately $3 \mathrm{~m}$ above the ground at the Alaska Railroad depot. A third wave, similar in nature to the second wave, but with less height, hit the town approximately $45 \mathrm{~s}$ after the second wave and reached an elevation of $9.2 \mathrm{~m}$ near the depot. There are no eyewitnesses to waves that struck the shore at other locations along Passage Canal. However, the inundation line was clearly evident from scattered debris and marks on fresh snow. The most elevated area inundated by waves was $32 \mathrm{~m}$ above the pre-earthquake Mean Low Water (MLW) and located along the northern shore of Passage Canal. Near the airstrip, the wave altitude topped $6.1 \mathrm{~m}$, while $400 \mathrm{~m}$ north, the inundation line was at $25 \mathrm{~m}$ altitude. Unless otherwise noted, altitudes and elevations are based on a preearthquake Mean Sea Level (MSL) datum and do not reflect the $1.6 \mathrm{~m}$ regional subsidence of the Whittier area during the earthquake. In Whittier, the maximum altitude reached by the wave was $13 \mathrm{~m}$ at the small boat harbor northeast of the Alaska Railroad depot. On the waterfront area, waves reached an altitude of $8 \mathrm{~m}$. A further description and analysis of the damage resulting from waves generated by submarine landslide at the port of Whittier is provided in Kachadoorian (1965).

Unlike residents of Valdez and Cordova who observed high waves late in the evening, Whittier residences noticed no "strange" waves in Passage Canal other than the two that struck during the earthquake. The tectonic tsunami should have arrived in Whittier no later than one hour after the earthquake, but was not observed and its damage to the port remains unknown.

\section{Tsunami hazards in Passage Canal}

Typical tsunami hazards to Alaska coastal communities originate from a coseismic displacement in the Gulf of Alaska, failing unconsolidated material, and a seiche wave (e.g. Wilson and Tørum, 1968; Plafker et al., 1969). During the 1964 event, all of these hazards became active and created an emergency situation in the city of Whittier. Kachadoorian (1965) and Wilson and Tørum (1968) argue that lateral tectonic movement of the land produced a seiche wave that might account for the observed "glassy hump" of water, while the second and third waves were landslide-generated. In this section, we list sources of the tsunami emergency in Whittier during the 1964 event.

\subsection{Seiche wave hazard}

When an earthquake occurs in a region with lateral variations in the bathymetry, there are two components of water motion: vertical and horizontal displacement of water due to the ocean bottom displacement. An experimental study by Iwasaki (1982) shows that if the slope of the ocean bottom is less than $1 / 3$, the tsunami is primarily generated by the vertical displacement of water and a wave produced by the horizontal displacement can be considered negligibly small. Applicability of this result to tsunamis in Indonesia and the Philippines was investigated by Tanioka and Satake (1996). In glacial fjords such as Passage Canal, the slope can exceed $1 / 3$, and hence the horizontal land motion can generate a local tsunami.

In addition to generation of gravity waves in the ocean, earthquakes can produce elastic oscillations of the water column due to benthic vibrations and the low compressibility of water (Miyoshi, 1954). Such elastic oscillations are typically characterized by a set of resonance frequencies, which can be present in a spectrum of the seismic waves. The 1964 Alaska earthquake, with the epicenter near Whittier, produced a broad spectrum of seismic waves, and thus could have triggered elastic oscillations in Passage Canal. In this sub-section, we consider a hypothetical hazard associated with elastic oscillations of the water.

In the case of a horizontal rigid bottom, resonance frequencies of the elastic oscillations are $v_{k}=c(1+2 k) / 4 H$, where $k=0,1,2, \ldots, c$ is the speed of sound in water, and 
$H$ is the ocean depth (Nosov and Kolesov, 2007). In the case of Passage Canal, $H \approx 200 \mathrm{~m}, c=1600 \mathrm{~m} \mathrm{~s}^{-1}$, and the lowest resonance frequency of the elastic oscillations is $v_{0} \approx 2 \mathrm{~Hz}$. Since there are no seismic records of the 1964 event near Whittier, it is impossible to reconstruct a vibration of the ocean bottom beneath Passage Canal. Therefore, we simulate the amplitude of the elastic waves generated in a 200-m-thick inviscid water column, initially at rest, and whose bottom starts to oscillate with $0.001 \mathrm{~m}$ amplitude and frequency $2 \mathrm{~Hz}$. One way to estimate the elastic waves in water is to solve the potential flow equation for an inviscid compressible water (Lamb, 1916). We employ an implicit finite difference method that is third-order accurate in time and fourth-order accurate in space.

Our modeling results show that the water column can absorb an unlimited amount of energy from the bottom oscillations. For example, after $60 \mathrm{~s}$ of the forced bottom oscillations, a wave generated on the water surface is approximately $0.48 \mathrm{~m}$ high. We note that a computed amplitude of the surface wave at the time $\tau$ is almost exactly equal to the total variation of the bottom oscillation with frequency $v_{0}$ over the time interval $[0, \tau]$. At a certain time, the small amplitude assumptions used to derive the flow equation can be violated, and the inviscid water column can rupture. Voids filled with air may appear in water (M. Nosov, personal communication, 2010). For example, the "boiling" water effect observed during the 1964 event within one of the glacial fjords in Alaska (Lemke, 1967) may be attributed to the air bubbles surfacing to the top of the water column. Further investigation is required. We emphasize that all oscillations of the sea bottom with frequencies $v<v_{0}$ cannot generate elastic waves in the wave, but can contribute to formation of gravity waves (Levin and Nosov, 2008).

In this article, we model a seiche wave in Passage Canal, while time averaging all high frequency oscillations and assuming that the land shifted laterally by $8.2 \mathrm{~m}$. Since there is no reliable seismic data to estimate dynamics of the lateral and vertical ground motion, we approximate an averaged lateral velocity $\boldsymbol{u}_{\mathrm{g}}$ of land displacement by a gaussian-shaped profile, similar to (e.g. Olsen and Archuleta, 1996). The time during which the displacement took place is unknown, and we thus consider three cases. In these cases, most of the displacement takes place within 10,20 , and $30 \mathrm{~s}$, respectively. The lateral land velocity $\boldsymbol{u}_{\mathrm{g}}$ for these cases is shown in Fig. 3.

\subsection{Landslide-generated tsunami hazard}

Kachadoorian (1965) shows convincing evidence that massive submarine landslides were triggered by the earthquake. Pre- and post-earthquake bathymetric data and sub-bottom profiles of the western part of Passage Canal are shown in Plate 3 by Kachadoorian (1965). The landslides in the western part of Passage Canal occurred on slopes ranging from $20^{\circ}$ to $30^{\circ}$. The slope failures occurred in delta

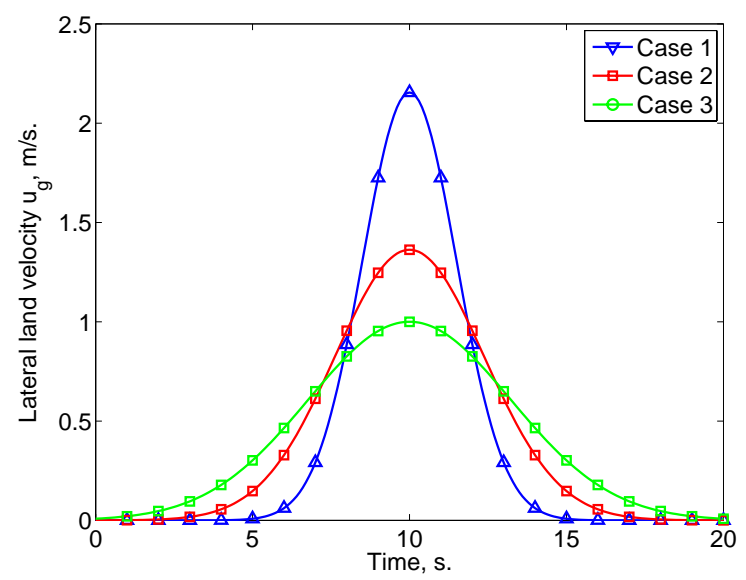

Fig. 3. Assumed lateral velocity of the land motion traverse the canal. The direction is shown in Fig. 2 by the red arrow. The total displacement for all cases is $8.2 \mathrm{~m}$.

sediments at the head of Passage Canal, in delta sediments and fill at Whittier waterfront, and possibly in a submarine lateral moraine along the northern shore of Passage Canal. It is still unknown whether landslides occurred in central and eastern parts of Passage Canal. It is highly probable that these landslides did not occur simultaneously, but rather at different moments during the earthquake.

Based on the pre- and post-earthquake bathymetry profiles, we approximate an initial distribution of the slide as follows. We digitize the post- and pre-earthquake bathymetry along $\mathrm{AA}^{\prime}, \mathrm{BB}^{\prime}$, and $\mathrm{CC}^{\prime}$ profile lines in Plate 3 by Kachadoorian (1965). Locations of these profile lines are shown by green lines in Fig. 2. The digitized pre- and post-earthquake bathymetry along the profiles is plotted in Fig. 4, by lines with hollow square and circle symbols, respectively. We also plot the present day bathymetry along the lines $\mathrm{AA}^{\prime}, \mathrm{BB}^{\prime}$, and $\mathrm{CC}^{\prime}$ in Fig. 4 by a line marked with solid circles. Note that we edited the DEM to remove postearthquake constructions such as the wave breaker, the cruise ship terminal, and some parts of the small boat harbor. The comparison of the post-earthquake bathymetry to the present day bathymetry along the shown profiles reveals that there are several discrepancies between these two profiles. The differences can be explained by digitizing, surveying, and measuring errors. Nevertheless, the present day bathymetry profiles quantitatively match the post-earthquake profiles in the area of landslide.

We digitally add some material above the present day bathymetry to match the pre-earthquake $\mathrm{AA}^{\prime}, \mathrm{BB}^{\prime}$, and $\mathrm{CC}^{\prime}$ profiles. The modeled landslide thicknesses are shown by lines marked with solid triangles in Fig. 4. Figure 5 shows locations and thicknesses of three complexes: namely, the Harbor, Airport, and Glacier (HAG) landslides. The Harbor and Airport landslide profiles fit the pre-earthquake bathymetry profiles, while there is little or no constraint on the Glacier landslide, whose existence is clearly marked in 


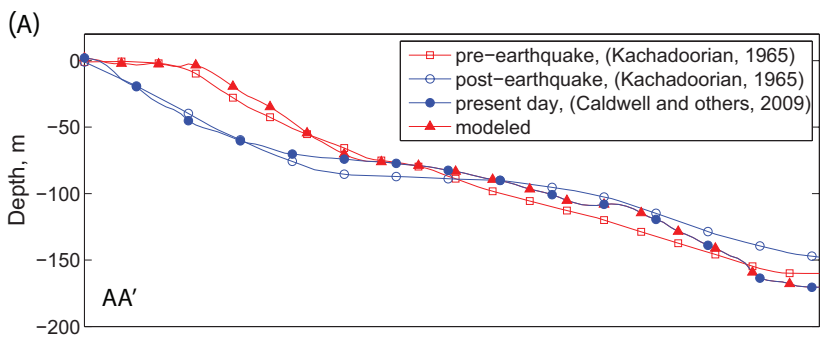

(B)

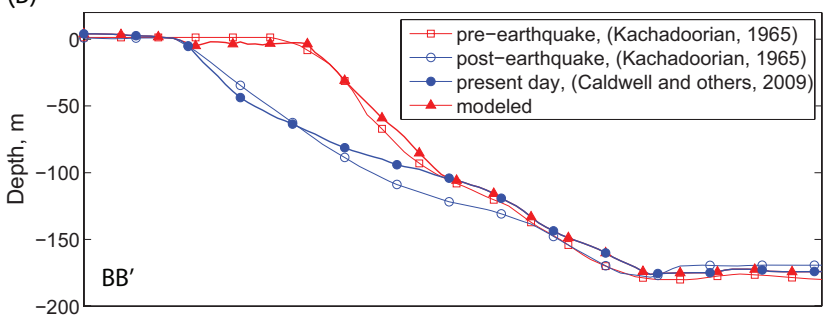

(C)

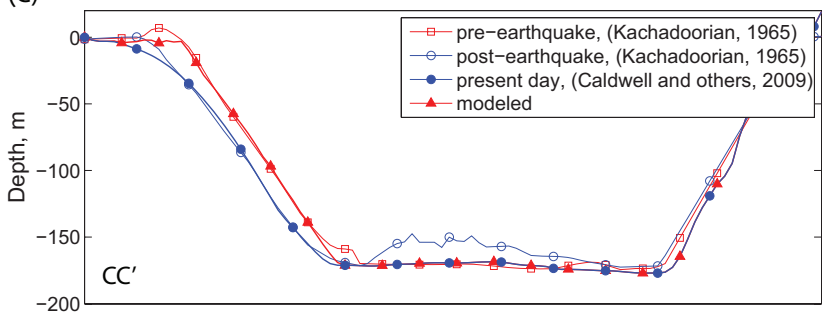

Fig. 4. Pre- and post-earthquake bathymetry profiles are shown by solid lines. The present day bathymetry profiles are shown by blue dotted lines. The modeled pre-1964 bathymetry profiles are shown by red dotted lines. The profile locations correspond to the transects $\mathrm{AA}^{\prime}, \mathrm{BB}^{\prime}$, and $\mathrm{CC}^{\prime}$ shown in Fig. 2.

Plate 3 by Kachadoorian (1965). We assume that the preearthquake bathymetry in the region occupied by the Glacier landslide had the same slope as the bathymetry in place of the Harbor and Airport landslides. Additionally, we assume that the volume of the Glacier landslide is half the volume of the Airport landslide. Based on these assumptions, we estimate that the total volume of these landslides is about $1.5 \times 10^{7} \mathrm{~m}^{3}$.

Kachadoorian (1965) provides a description of landslides at the head of Passage Canal during the 1964 event and hypothesizes regarding a landslide offshore of the Billings Creek delta. Kachadoorian (1965) also mentions that the waves that struck the west coastline of Passage Canal originated along the north coastline of the canal and traveled southwest. Consequently, we consider another possible landslide location at the northern shore of Passage Canal. Unfortunately, there is no bathymetry data to adequately constrain locations and thicknesses of underwater slides anywhere in Passage Canal, except at its head. In Table 1, we list all considered landslides with the corresponding volume of the sliding ground.
Table 1. Considered landslide locations.

\begin{tabular}{lll}
\hline Scenario & Landslide location & $\begin{array}{l}\text { Volume, } \\
10^{6} \mathrm{~m}^{3}\end{array}$ \\
\hline 1 & Harbor-Airport-Glacier (HAG) & 15 \\
2 & Northern shore & 10 \\
3 & Billings Creek delta & 10 \\
4 & All locations & 35 \\
\hline
\end{tabular}

Even though the residents of Whittier did not notice the tectonic tsunami wave, we model its impact on the city infrastructure. In the next section, we briefly describe available coseismic deformation models of the 1964 event.

\subsection{Tectonic tsunami hazard}

Passage Canal is located near a plate boundary, where the Pacific and North American plates converge along the Aleutian Megathrust (DeMets et al., 1990; Page et al., 1991). According to the segmentation model of Nishenko and Jacob (1990), southcentral Alaska includes three segments of the megathrust: the Yakataga-Yakutat (YY), Prince William Sound (PWS), and Kodiak Island (KI) segments, shown in Fig. 1. Using seismic wavefront data, Christensen and Beck (1994) show that there were two areas of high moment release, representing the two major asperities of the 1964 rupture zone: the PWS asperity with an average slip of $18 \mathrm{~m}$, and the KI asperity with an average slip of $10 \mathrm{~m}$. The YY area at the eastern end of the megathrust did not rupture during the 1964 event. We note that the interaction between the Yakutat block and the Pacific and North America plates is complex and poorly understood, an interested reader can find further information in (e.g. Nishenko and Jacob, 1990; Carver and Plafker, 2008).

The 1964 tsunami was generated in the trench, upper plate fold, and thrust belt area of PWS and KI segments (Plafker, 1965; Wilson and Tørum, 1968). Holdahl and Sauber (1994) applied Plafker's description of the megathrust displacement and implemented an inversion of geodetic data to construct a model of the coseismic displacement during the 1964 event as well as the motion of the Patton Bay fault, located along Montague Island. Johnson et al. (1996) refined results of Holdahl and Sauber and accomplished a joint inversion of geodetic and tsunami data to reconstruct a coseismic deformation model of the 1964 earthquake. Suito and Freymueller (2009) found that they could not fit collected Global Positioning System (GPS) data accurately unless they increase the mapped extent of the fault. In the same report, Suito and Freymueller (2009) develop a coseismic deformation model of the 1964 earthquake based on a 3-D viscoelastic model, which implements a realistic geometry with an elastic slab. This coseismic model is not based 

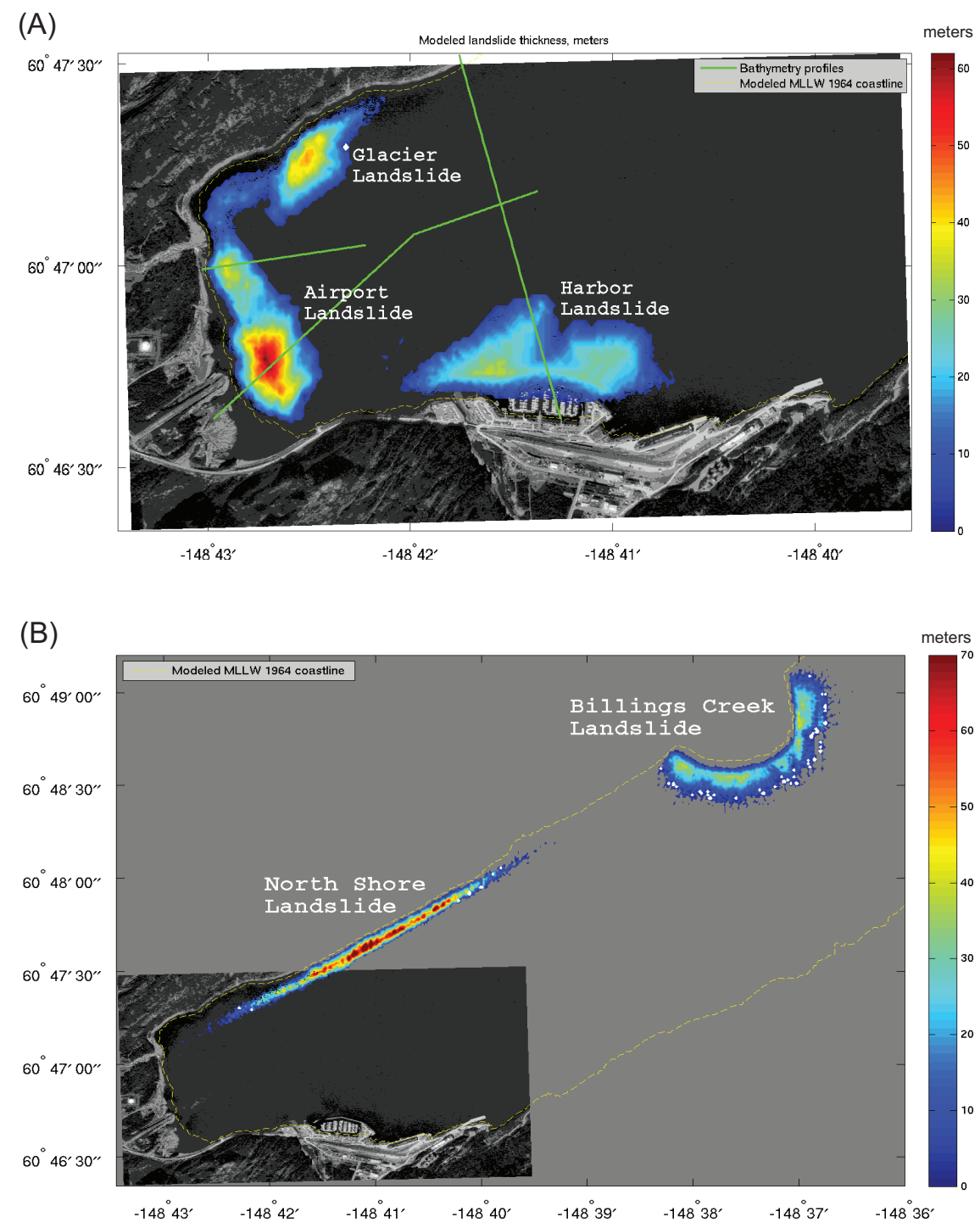

Fig. 5. The initial thickness of landslides. The upper plot shows the Harbor-Airport-Glacier (HAG) landslide complex, $1.5 \times 10^{7} \mathrm{~m}^{3}$ in volume. The bottom plot shows locations and thicknesses of the North shore and Billings Creek landslides. Each landslide is $1.0 \times 10^{7} \mathrm{~m}^{3}$. The location of bathymetry profiles used to constrain the HAG landslide are shown by green lines. The modeled MLLW shoreline before the earthquake is shown by a dashed yellow line.

on an inversion of tsunami data, but resembles a recently published inversion model (Ichinose et al., 2007) as well as some previously proposed models (e.g. Holdahl and Sauber, 1994; Johnson et al., 1996; Santini et al., 2003).

In this study, we use two coseismic deformation models of the 1964 earthquake, namely the Johnson et al. (1996) and the Suito and Freymueller (2009) models to simulate vertical displacements of the sea floor during the earthquake. The following abbreviations will be referenced throughout this report: JDM for the former and SDM for the latter. The main difference between JDM and SDM is that the latter finds slightly higher slip near the down-dip end of the rupture, in order to explain the horizontal displacements. Additionally, the rupture in the SDM is assumed to occur deeper than it is in the JDM. The deeper subfaults in the SDM produce smoother variation of the sea floor deformation than in the JDM. An interested reader can find further comparison of the JDM and SDM in (Suleimani et al., 2010).

\section{Description of models and computational grids}

The observed water waves during and shortly after the 1964 earthquake were generated by different physical mechanisms and have to be separately modeled. In this section, we briefly describe models for propagation and runup of the tectonic and landslide-generated tsunamis as well as the gravity seiche wave. 


\subsection{A tectonic tsunami model}

Currently, there is a series of approaches suitable for simulation of tsunami wave propagation and runup, ranging from application of primitive threshold-type models (e.g. Shuto, 1991) to computation of the water dynamics by the 3-D Navier-Stokes equations (e.g. Dalrymple and Rogers, 2006). Simulation of the entire tsunami wave from its generation by an earthquake to runup by solving the 3-D Navier-Stokes equations is impractical due to limitations in modern computational resources. However, the classical non-linear shallow water equations - an approximation to the 3-D Navier-Stokes equations - is widely and successfully exploited to simulate propagation of tsunami waves (Liu et al., 1991; Yeh et al., 1994; Titov and Synolakis, 1998).

The water depth $\eta$ and the horizontal water velocity $\boldsymbol{v}$ in the ocean are described in the spherical coordinates by the mass conservation principle

$$
\frac{\partial \eta}{\partial t}+\nabla \cdot(\eta \boldsymbol{v})=0
$$

and the linear momentum conservation law

$\frac{\partial(\eta \boldsymbol{v})}{\partial t}+\nabla \cdot(\boldsymbol{v} \eta \boldsymbol{v})=-g \eta \nabla \zeta-f \eta\left(\boldsymbol{e}_{\mathrm{r}} \times \boldsymbol{v}\right)+\eta \boldsymbol{\tau}$

Here,

$\zeta=h+\eta$

is the water level, $h$ is the bathymetry, $g$ is the acceleration of gravity, $f$ is the Coriolis parameter, $\boldsymbol{e}_{\mathrm{r}}$ is the outward unit normal vector on the sphere, and the term $\tau$ represents the bottom friction.

The shallow water approximations have proven to be robust enough not only to simulate propagation of the tsunami but also to predict runup of both non-breaking and mildly breaking waves (Synolakis, 1986). This property of the shallow water equations is useful in modeling of tsunami in most geophysical conditions.

Due to non-linearity, shallow water equations do not have an analytical solution for an arbitrary initial and boundary conditions, and its solution is typically computed by numerical methods (Titov and Synolakis, 1995; Imamura, 1995; Liu et al., 1998); an interested reader is referred to (Kowalik and Murty, 1993a; Imamura, 1996) where a detailed review of finite difference schemes is given. In total, more than ten numerical methods including (Mader and Lukas, 1984; Kowalik and Murty, 1993b; Kirby et al., 1998; Lynett and Liu, 2002; George and LeVeque, 2006; Zhang and Baptista, 2008; Nicolsky et al., 2010a) for the simulation of tsunamis have developed in the last twenty years. To simulate propagation and runup of the tectonic tsunami in Whittier, we use a verified numerical model that exploits a domain decomposition technique and allows for efficient parallelization of the runup algorithm; consult (Nicolsky et al., 2010a) for further details.

\subsection{A landslide-generated tsunami model}

A number of studies of landslide-generated tsunamis employ depth-integrated numerical models. Harbitz (1992) simulated tsunamis generated by Storegga slides using linear shallow water equations. Jiang and LeBlond (1992, 1994); Fine et al. (1998); Thomson et al. (2001); Imamura et al. (2001); Titov and Gonzalez (2001) used non-linear shallow water approximation to model the slide-water system as a two-layer flow. Lynett and Liu (2002) discussed the limitations of the depth-integrated models with regard to landslide-generated waves, and developed fully nonlinear weakly dispersive model for submarine slides that is capable of simulating waves from relatively deep water to shallow water. The model was later extended to employ the multilayer approach (Lynett and Liu, 2004a,b) that allowed for accurate simulation of landslides in shallow and intermediate water (Lynett and Liu, 2005). Grilli and Watts (2005) derived and validated a two-dimensional fully nonlinear dispersive model that does not have any restrictions on tsunami amplitude, wavelength, or landslide depth, and describes the motion of the landslide by that of its center of mass.

To simulate tsunamis produced by multiple underwater slope failures in Passage Canal on 27 March 1964, we used a three-dimensional numerical model of a viscous underwater slide that is coupled with shallow water Eqs. (1)-(2) by substituting Eq. (3) with

$\zeta=h+s+\eta$,

where $s \geq 0$ is the landslide thickness. The thickness $s$ is computed exploiting assumptions regarding a rheology of the landslide and the water pressure (i.e. the total water depth $\eta$ and bathymetry $h$ ). This coupling was initially proposed by Jiang and LeBlond (1992), improved by Fine et al. (1998) and successfully used by Suleimani et al. (2009) to model landslide-generated tsunami in Resurrection Bay, a glacial fjord similar to Passage Canal. The model uses a long-wave approximation to water waves and the deforming slide, which means that the wavelength is much greater than the local water depth, and that the slide thickness is much smaller than the characteristic length of the slide along the slope (Jiang and LeBlond, 1994). Assier-Rzadkiewicz et al. (1997) argued that the long-wave approximation could be inaccurate for slopes exceeding $10^{\circ}$. Rabinovich et al. (2003) studied the validity of the longwave approximation for slopes greater than $10^{\circ}$ and found that for a slope of $16^{\circ}$, the possible error was $8 \%$, and for the maximum slope in their study of $23^{\circ}$, the possible error was $15 \%$. Since the pre-earthquake offshore slopes average of $10^{\circ}$ to $30^{\circ}$ in the vicinity of Whittier, the possible error introduced by a slide moving down these steeper slopes could be around $20 \%-30 \%$. We note that the advantage of this vertically integrated model, which includes two 
horizontal dimension effects, is its ability to simulate real landslide tsunami events using high-resolution numerical grids.

\subsection{A seiche wave model}

Early studies of the gravity surface seiche waves were undertaken by Lamb (1916); Kvale (1953); Proudman (1953); and McGarr (1965). An interested reader is referred to (Barberopoulou et al., 2006) and references therein for a brief review of the seiche modeling studies. Typically it is assumed that the shallow water Eqs. (1)-(2) are suitable to model a gravity seiche wave in a channel or in a lake (e.g. Kowalik and Murty, 1993b; Synolakis, 2003). For example, to model a seiche wave in a channel, McGarr (1965) proposes to use a non-inertial reference frame as follows. An accelerated coordinate system is replaced by a non-accelerated system with an induced fictitious horizontal force $f$ (Arnold, 1989). Consequently, the momentum conservation principle (2) is augmented by the forcing term $f \approx d \boldsymbol{u}_{\mathrm{g}} / d t$, where $\boldsymbol{u}_{\mathrm{g}}$ is the velocity of land, and $d / d t$ is the time derivative. This approach is successfully implemented by Gardarsson (1997) to model shallow water sloshing in a laboratory tank and by Barberopoulou et al. (2006) to model seiche waves in a certain lake.

We emphasize that adding the fictitious force $f$ to the right hand side of (2) leads to an instantaneous water motion in an entire water reservoir when the reservoir boundaries were displaced. This physical behavior can model the seiche wave in the reservoir only if the time, when $\boldsymbol{u}_{\mathrm{g}}$ significantly varies, $\tau$, is greater than the longest natural period, $T$, for a seiche in the reservoir. Otherwise, a lateral displacement of reservoir boundaries does not have enough time to cause displacement of water in the entire reservoir. In the case of Passage Canal, we approximate $T$ by the longest natural period $T_{0}$ for a seiche in an enclosed rectangular body of water. This approximation is made according to Merian's formula (Merian, 1828)

$T_{0}=\frac{2 L}{\sqrt{g H}}$,

where $L$ and $H$ are the width and depth of the basin, respectively. We assume that for Passage Canal, $L \approx 700 \mathrm{~m}$ and $H \approx 200 \mathrm{~m}$, and hence $T \approx 30 \mathrm{~s}$. Therefore, using the forcing term, $f$, to model a seiche in Passage Canal is not applicable since the land displacement, described by Cases 1, 2 and 3, Fig. 3, takes between 10 and $20 \mathrm{~s}$.

In this work, we consider a fixed coordinate system and model the motion of the reservoir during an earthquake by solving Eqs. (1)-(2) while taking into account that $h=$ $h(\mathrm{x}, \mathrm{y}, t)$. Since the lateral land velocity $\boldsymbol{u}_{\mathrm{g}}$ is known, we find that

$\frac{\partial h}{\partial t}=\boldsymbol{u}_{\mathrm{g}} \cdot \nabla h, \quad h(\mathrm{x}, \mathrm{y}, 0)=h_{0}(\mathrm{x}, \mathrm{y})$, where $h_{0}(\mathrm{x}, \mathrm{y})$ is the pre-earthquake bathymetry. Equations (1)-(2) and (5) are discretized in Cartesian coordinates by finite differences on Arakawa C-grid (Arakawa and Lamb, 1977). The spatial derivatives are discretized by central difference and upwind difference schemes (Fletcher, 1991). The runup of seiche waves is modeled by the same method as the one utilized to simulate the runup of tectonic waves (Nicolsky et al., 2010a).

Besides selection of the appropriate wave model and its numerical implementation, it is also necessary to construct a bathymetry/topography DEM of Passage Canal and nearby areas. In the next subsection, we describe development of certain DEMs used in simulating the tectonic, landslidegenerated and seiche waves in Passage Canal.

\subsection{Grid development and vertical datums}

To compute inundation caused by a tectonic tsunami, we employ a series of nested computational grids. The bathymetric and topographic relief in each nested grid is based on DEMs developed at the National Geophysical Data Center, National Oceanic and Atmospheric Administration (NOAA), in Boulder, Colorado. The coarsest grid, with the resolution of 2-arc-min, spans central and northern Pacific Ocean, while the highest resolution grid, with the resolution of approximately $15 \mathrm{~m}$, is localized near Passage Canal, including Shotgun Cove. All developed DEMs have the common Mean Higher High Water (MHHW) vertical datum. A detailed description of the data sources and methodology used to develop high resolution, 8/3-, 8-, and 24-arc-s DEMs is described in great detail by Caldwell et al. (2009) and Lim et al. (2009).

We conducted a high resolution differential GPS survey (real time kinematic) within the Whittier harbor and adjacent areas. Taking into account that GPS measurements are taken with respect to the World Geodetic System 1984 (WGS84) ellipsoid, elevation heights need to be adjusted to the MHHW datum as follows. During the survey, dynamics of the sea surface height, denoted by $\mathrm{H}_{2}$ in Fig. 6, was measured by the GPS several times during a high tide as well as at some levels between MHHW and MLLW. Since the sea surface height measurements $H_{2}(t)$ are taken with respect to the WGS84 ellipsoid and tide level $H_{1}(t)$ is known at any time $t$ during the survey (predictions by NOAA Tides and Currents, http://tidesandcurrents.noaa.gov/), it is easy to estimate a vertical shift between the MHHW and WGS84 geodetic datum by fitting the measured sea heights to the predicted ones shown in Fig. 6b. Once this correction is made, we convert the collected GPS measurements to the MHHW datum. Since the real-time kinematic correction was used during the survey, the error of collected points with respect to each other is within several centimeters (Geosystem, 2002); the error of converting the observations to the MHHW datum does not exceed one meter. We interpolate between the collected measurements in certain areas of flat topography 
(A)

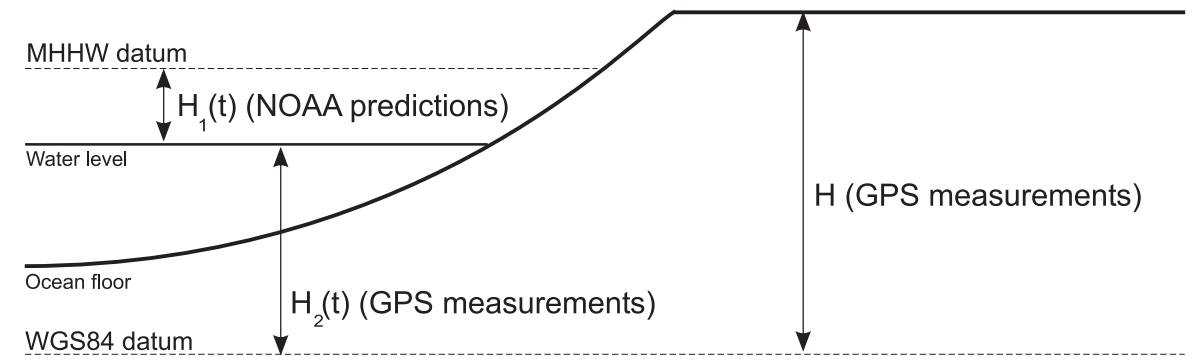

(B)

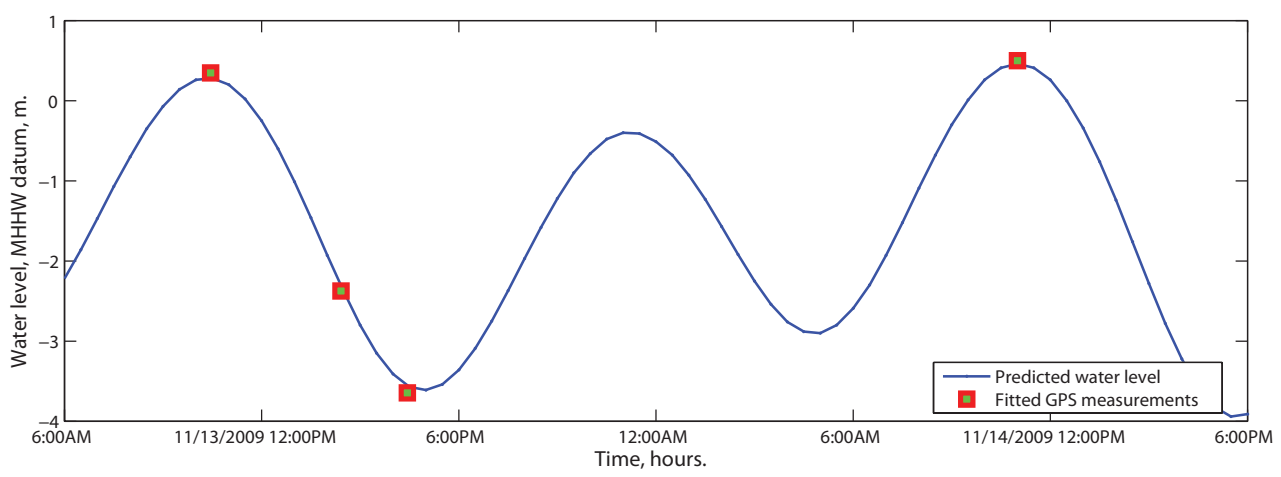

Fig. 6. (A) Measurement of sea level in the WGS84 datum and the relation of the WGS84 datum to the MHHW datum. (B) Predicted water level dynamics in Whittier and the fitted GPS measurements of the water level in the MHHW datum.

such as the railroad tracks, harbor parking area, and ferry terminal, taking into account relatively sparse distribution of the GPS measurements. In Fig. 2, we show the adjusted DEM within the Whittier downtown area. The 0-, 5-, and 10$\mathrm{m}$ elevation contours are marked by solid lines. As the result of incorporating the GPS data, the parking area, railroad depot, and tracks have a more uniform horizontal level (City Manager M. Earnest, personal communications the during a visit to Whittier, 2009) than without incorporating the GPS measurements.

Before proceeding to modeling the tsunami waves, we recall that at the time of the main shock the water level was $0.3 \mathrm{~m}$ above the MLLW (Kachadoorian, 1965). A sketch of the water level in Passage Canal just before the earthquake is shown in Fig. 7a. During the earthquake, the Whittier area subsided by $S=1.6 \mathrm{~m}$. It is not known when chronologically the subsidence occurred, i.e. before, during, or after the landslide-generated tsunami. In this report, we assume that the subsidence occurred within seconds after the main shock. A sketch of the Whittier harbor and landslide-generated tsunami is shown in Fig. 7b. In order to reconstruct the sea level at Whittier after the earthquake, but before arrival of the tectonic tsunami, we first convert the DEM from the postearthquake MHHW datum to the pre-earthquake MHHW datum by adding the subsidence $S$, Fig. 7c. Then, we lower the sea level in the edited DEM to $0.3 \mathrm{~m}$ above the MLLW level. We note that all post-1964 constructions such as the terminal for cruise ships and harbor are digitally removed from the DEM.

\section{Numerical modeling of the 1964 tsunami in Passage Canal}

In this section, we compare inundation modeling results of the 1964 tsunami in Passage Canal with eyewitness observations.

\subsection{Modeling of the seiche wave}

The first observed wave in Passage Canal was considered to be a seiche wave caused by the $8.2 \mathrm{~m}$ land displacement transverse Passage Canal (Kachadoorian, 1965; Wilson and Tørum, 1968). The direction of displacement is shown by a red arrow in Fig. 2. Numerical modeling shows that the land displacement causes a drawdown of water at the harbor and wave formation along the northern shore. This wave propagates transverse to Passage Canal and, from the point of view of an observer in downtown Whittier, might resemble a "glassy hump" of water. The height of the simulated wave, while it propagates across the canal towards the southern shore, is approximately $5-10 \mathrm{~m}$ and agrees with eyewitness observations. In Fig. 8, we plot the modeled sea level dynamics near the Whittier harbor and note that 
(A)

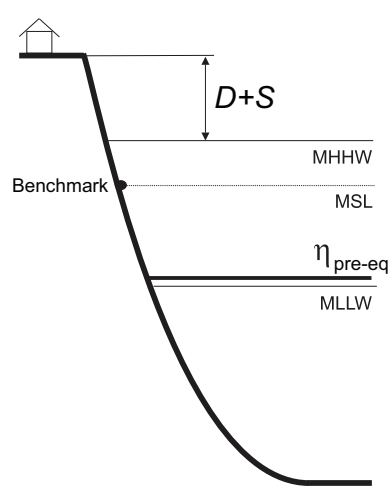

(B)

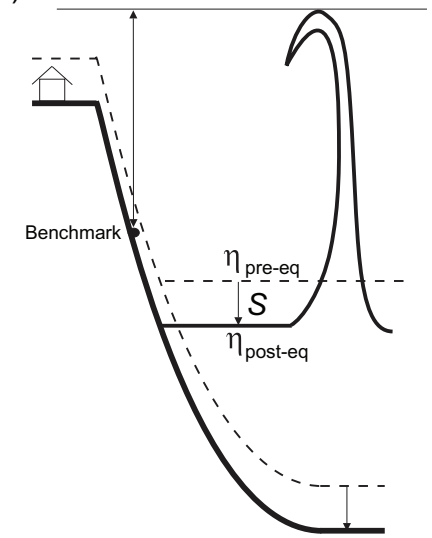

(C)

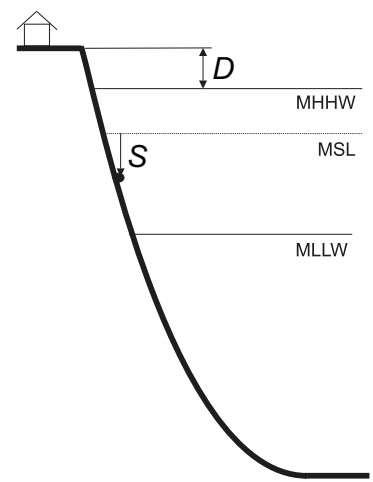

Fig. 7. A schematic drawing of the city harbor before the earthquake (A), after the earthquake during the landslide-generated tsunami (B), and the present day $(\mathbf{C})$.

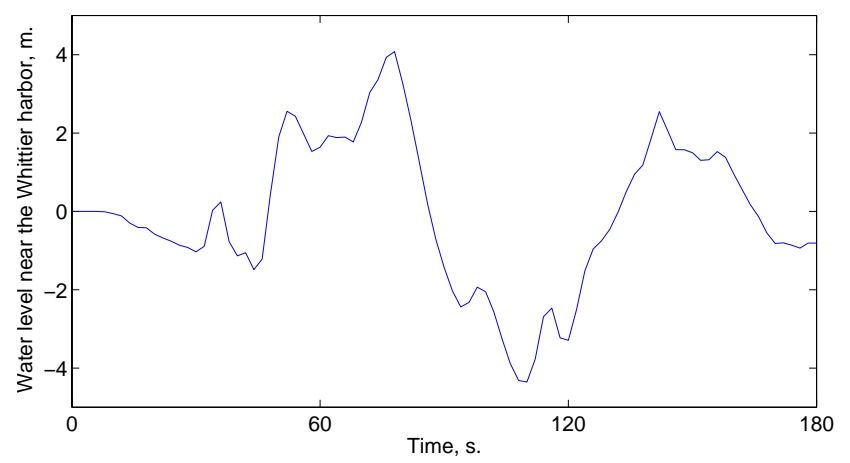

Fig. 8. Modeled height of the seiche wave near the Whittier harbor, Case 1. The drawdown of water occurs after $10 \mathrm{~s}$, at the moment of the maximum lateral land velocity $\boldsymbol{u}_{\mathrm{g}}$, see Fig. 3 .

the simulated wave height near the Whittier waterfront is about $4 \mathrm{~m}$. However, in other locations along the southern shoreline, the runup in numerical experiments can be as high as $10 \mathrm{~m}$ a.s.l. Since the modeled seiche wave has a short wavelength, it breaks near the coastline and does not significantly penetrate inland. This might explain why there are no observations of runup from the first wave in Passage Canal.

The computed inundation in all three cases of the land displacement are shown in Fig. 9. The simulated inundation zones are almost identical. In the third case, the land shifted in $10 \mathrm{~s}$, and the inundation zone is slightly larger than in the other two cases. These numerical experiments let us conclude that the duration when the displacement took place does not notably affect the inundation, and the inundation primarily depends on the amount of the lateral displacement of land. The observed inundation, marked by a yellow line in Fig. 9, is much further inland than any inundation line due to the modeled seiche wave. We conclude that the other locally generated waves penetrated further inland and caused the significant destruction in Whittier during the 1964 event.

\subsection{Modeling of two landslide-generated waves}

According to Kachadoorian (1965), between 60 and $90 \mathrm{~s}$ after subsidence of the glassy hump of water, a muddy bore of water inundated the downtown area of Whittier. This wave has been attributed to the landslide-generated tsunami and is modeled in this report. We model the seiche and landslide-generated waves separately, since the landslidegenerated wave inundated the city at least $60 \mathrm{~s}$ after the seiche wave. By this time, the seiche wave has already scattered and can be considered small with respect to the landslidegenerated waves, e.g. the amplitude of the modeled seiche wave decreased almost twice in $60 \mathrm{~s}$ after it hit the Whittier waterfront, see Fig. 8.

We assume that the slide-prone unconsolidated deposits are initially at rest and are triggered into sliding by ground shaking. The slide material moves thereafter only under the force of gravity. Shannon and Hilts (1973) conducted a sub-surface geotechnical investigation of materials that failed in settings similar to Passage Canal, finding that the density of the slide material ranged from $2000 \mathrm{~kg} \mathrm{~m}^{-3}$ to $2110 \mathrm{~kg} \mathrm{~m}^{-3}$. There are no measurements of the slide viscosity, but sensitivity studies by Rabinovich et al. (2003) demonstrate that the influence of kinematic viscosity on tsunami height is not significant. We assume slide density $2000 \mathrm{~kg} \mathrm{~m}^{-3}$ and slide viscosity of $0.05 \mathrm{~m} \mathrm{~s}^{-2}$. The slide thickness is shown in Fig. 5. At the open boundary of the numerical grid, we specify the radiation boundary condition for the water waves. We numerically model triggering of the landslide and simulate the landslide-generated tsunamis in Passage Canal for 5 min with a $0.01 \mathrm{~s}$ time step.

Figure 10 shows modeled inundation by tsunamis generated by ground failures according to scenarios 1, 2, and 3 of Table 1. The observed extent of inundation after the 1964 earthquake is shown by the solid yellow line. Before proceeding to analyze the modeling results, we emphasize an interesting fact: there was no observed inundation behind 


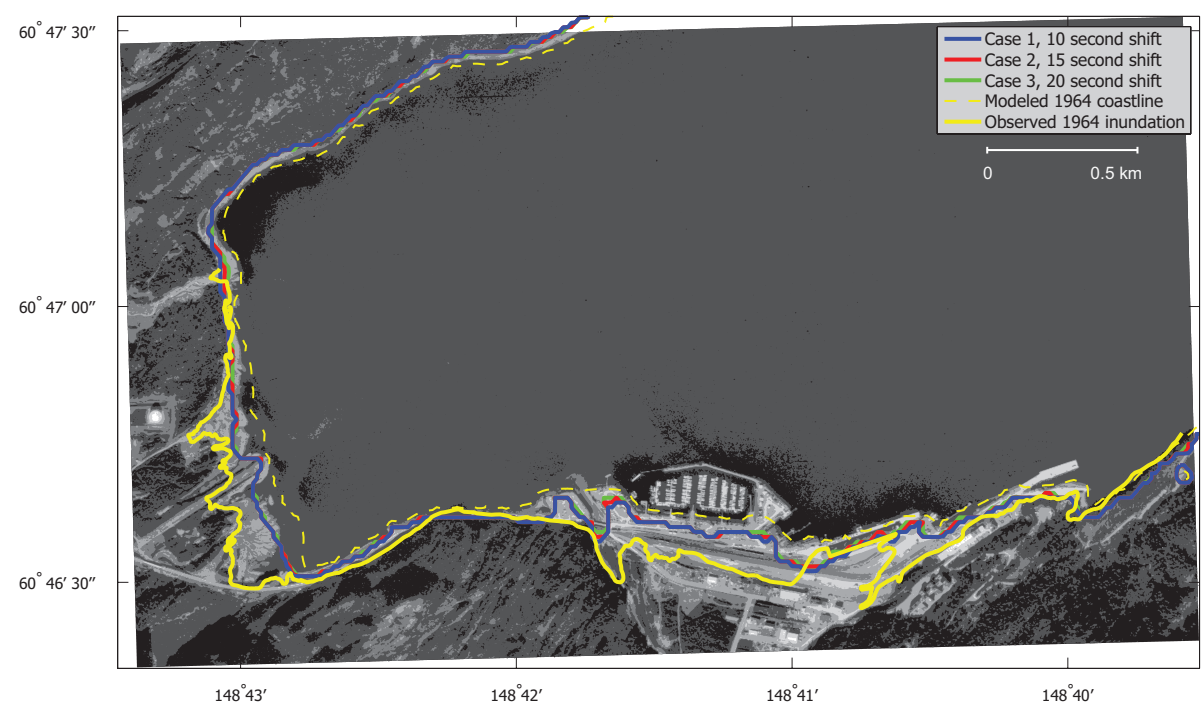

Fig. 9. Maximum computed runup by seiche waves in Passage Canal during the 1964 event. The yellow line represents the observed inundation after the 1964 tsunami. The modeled MLLW shoreline before the earthquake is shown by a dashed yellow line.

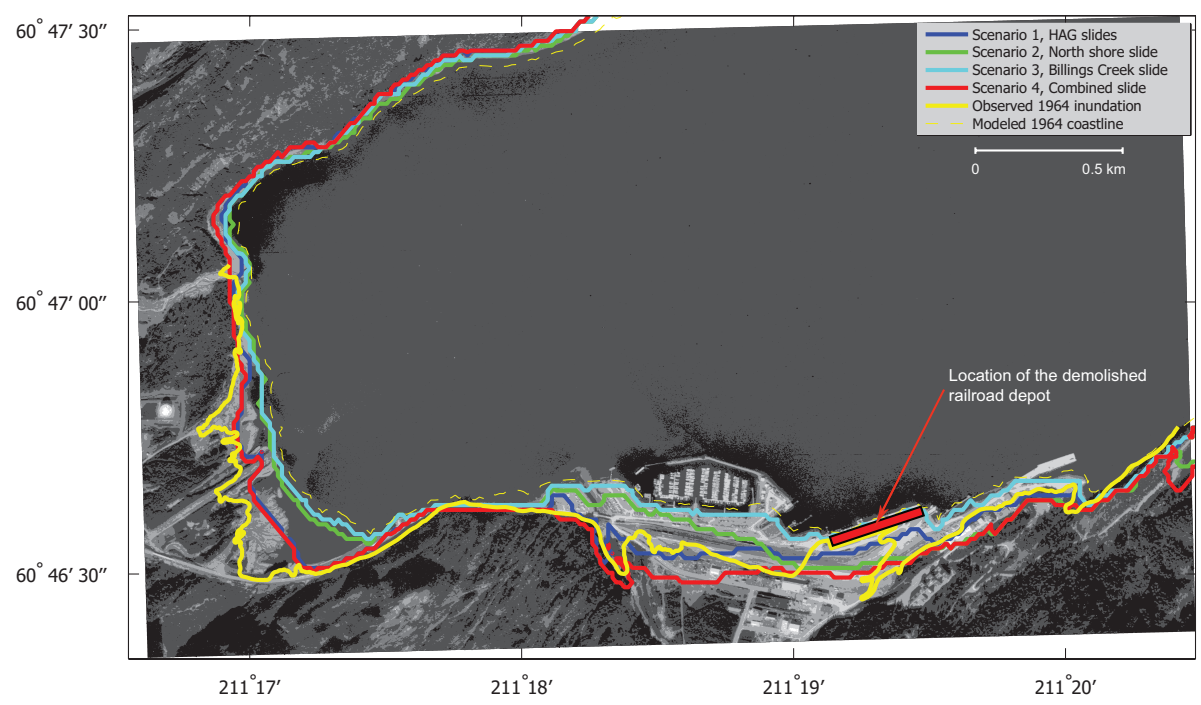

Fig. 10. Maximum computed runup by landslide-generated tsunami waves in Passage Canal during the 1964 event. The yellow line represents the observed inundation after the 1964 tsunami. The modeled MLLW shoreline before the earthquake is shown by a dashed yellow line.

the reinforced concrete building of the railroad depot (shown by a red rectangle in Fig. 10) during the 1964 event. This fact reveals that the tsunami that hit the depot was traveling in the southwest direction. We also recall that Kachadoorian (1965) mentions that the waves originated along the north coastline of the canal and traveled in the southwest direction. Since the current version of the DEM lacks the recently demolished railroad building, which protected an area behind it from a tsunami attack, the modeled runup should significantly extend inland and "fill the gap" behind the depot.
In Fig. 10, the modeling results show a directivity pattern of the inundation corresponding to each landslide-generated tsunami. The landsliding at the harbor, airport and glacier, i.e. the HAG slide, triggers a tsunami, causesing significant inundation (blue line) at the head of Passage Canal and western side of downtown Whittier, whereas the inundation (green line) by North shore landslide-generated tsunami is localized at the eastern part of the town, particularly near the railroad depot. The energy of the Billings Creek landslidegenerated tsunami is primarily directed towards the south coast. It quickly dissipates in the direction of the harbor area and causes an insignificant inundation (cyan line) beyond the coastline (dashed yellow line). 


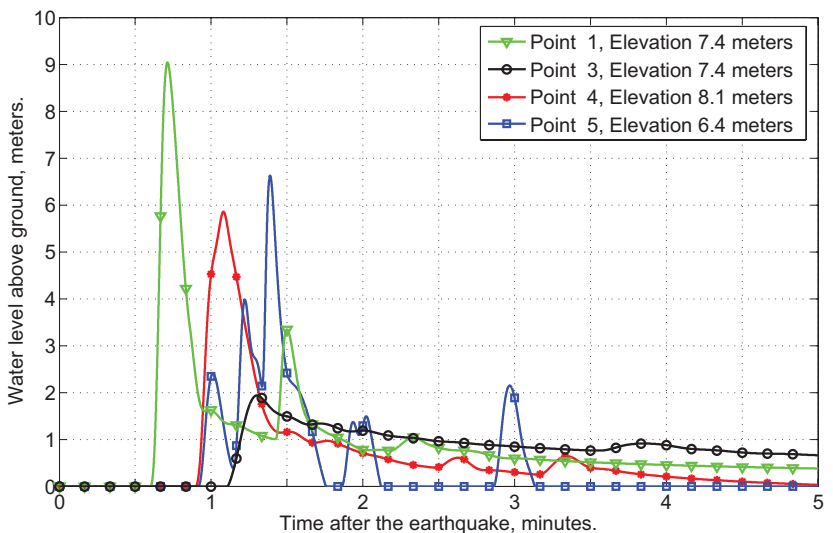

Fig. 11. Landslide-generated wave level above ground at certain locations near the Whittier water front. Location of Points 1, 3, 4 and 5 are shown in Fig. 2. The elevation of each point is with respect to the pre-earthquake sea level that was $0.3 \mathrm{~m}$ above the MLLW. The difference between the MSL and MLLW is approximately $1.7 \mathrm{~m}$.

Taking into account that the HAG landslide configuration is roughly approximated by the bathymetry difference profiles, the modeling results show a good comparison with observations in the western part of the downtown. On the other side of the downtown, the simulated tsunami generated by the North shore slide captures the observed southwesttraveling wave and inundates the area behind the depot. However, the modeled inundation extent is less than the observed one. In scenario 4 , we simulate tsunami waves when all landslides occur simultaneously. Although it is likely that individual slides were triggered at different times during or after the ground shaking, there is neither evidence to support nor to reject this hypothesis.

In scenario 4, we assume that all slides are initially at rest and are simultaneously triggered into motion by ground shaking. The resultant modeled inundation (red line) significantly extends inland particularly within the entire downtown area. The discrepancy between the modeled and observed inundation in the western part of Whittier can be explained by presence of a significant flat area in the present DEM (the parking lot, constructed after the 1964 event, altered the topography). Within this flat area, the waves triggered by the HAG and North slides arrive almost at the same time and collide with each other. Note that a small temporal delay in landslide failures can change arrival time of these waves and modify their nonlinear interference. Regrettably, the information regarding the timing of landslide failure remains unknown. The information regarding the $45 \mathrm{~s}$ time delay between arrivals of two landslide-generated waves is not sufficient, since it is unclear whether Kachadoorian (1965) refers to a certain location or to different parts of the town.
Figure 10 shows that the model captures an extreme runup at the northern shore of Passage Canal. The highest modeled value of runup at the northern shore is about $24 \mathrm{~m}$ above the pre-earthquake MSL, whereas the inundation at approximately $32 \mathrm{~m}$ was observed at the same point after the 1964 event. Figure 11 shows water level dynamics at several locations along the Whittier waterfront. The highest wave, with an altitude of $13 \mathrm{~m}$ with respect to the pre-earthquake MSL, was recorded at the small boat harbor (Point 5, Fig. 2). Our numerical modeling reveals that the wave reached $6.5 \mathrm{~m}$ above ground at this area, which is approximately $6.4 \mathrm{~m}$ a.s.l. at the onset of the earthquake, or approximately $4.8 \mathrm{~m}$ above the pre-earthquake MSL. Therefore, the computed maximum wave height of $6.5+4.8=11.3 \mathrm{~m}$ at Point 5 quantitatively agrees with the observed $13 \mathrm{~m}$ wave at this point. According to eyewitnesses, a wave rose to a $12 \mathrm{~m}$ altitude at the railroad depot near Point 4 . The numerical calculations at this point show that the wave height was $6 \mathrm{~m}$ above the ground at this point, that is $6.4 \mathrm{~m}$ above the pre-earthquake MSL. Consequently, our computations show that the wave reached a $12.4 \mathrm{~m}$ altitude. Even though the model captures the observed wave heights at the eastern part of Whittier (Points 4 and 5), the modeled extent of inundation is further inland than the observed one along Depot Rd. At the location of the completely destroyed Columbia Lumber Co. (Point 1 , Fig. 2) on the right bank of Whittier Creek, the modeled wave reached $9 \mathrm{~m}$ above ground, sufficient to disintegrate industrial buildings and scatter debris, shown in an aerial photography after the 1964 event (Kachadoorian, 1965).

Although the model captures the south-southwesttraveling waves that struck the southern shore of Passage Canal about $1000 \mathrm{~m}$ west of Whittier Creek with tremendous force (Kachadoorian, 1965), the modeled wave heights are less than the observed ones. The reported runup in this area was approximately $15 \mathrm{~m}$, whereas the numerically modeled runup is only $7 \mathrm{~m}$. The disparity between modeling results and observations suggests that multiple landslides likely occurred at the northern shore of Passage Canal. Without adequate bathymetry, it is difficult to constrain their locations and thicknesses.

\subsection{Modeling the unnoticed tectonic tsunami}

Preliminary computations show that it takes approximately 30-60 min for a tsunami generated in the Gulf of Alaska to travel into Passage Canal. By this time, locally generated waves cease and thus the landslide-generated and tectonic tsunamis in Passage Canal can be considered as independent events. To model propagation and runup of the tectonic tsunami, we use a series of nested grids. Recall that the lowest resolution 2-arc-min grid spans the Gulf of Alaska, while the finest resolution 15-m grid covers Passage Canal, Alaska. In this article, we use the JDM and SDM of the coseismic deformation for the 1964 event. Even though these models differ significantly in the Gulf of Alaska, the 


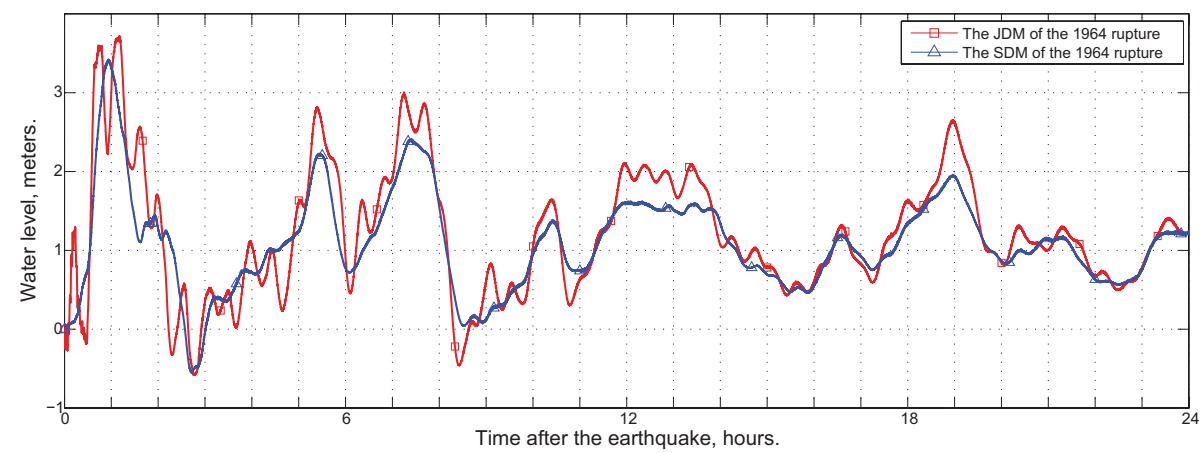

Fig. 12. Modeled water level dynamics at Point 2 (Fig. 2) in the Whittier harbor during the 1964 tectonic tsunami, based on the SDM and JDM. A change in the sea level due to tides is not modeled. Elevation in meters with respect to the post-earthquake MLLW datum.

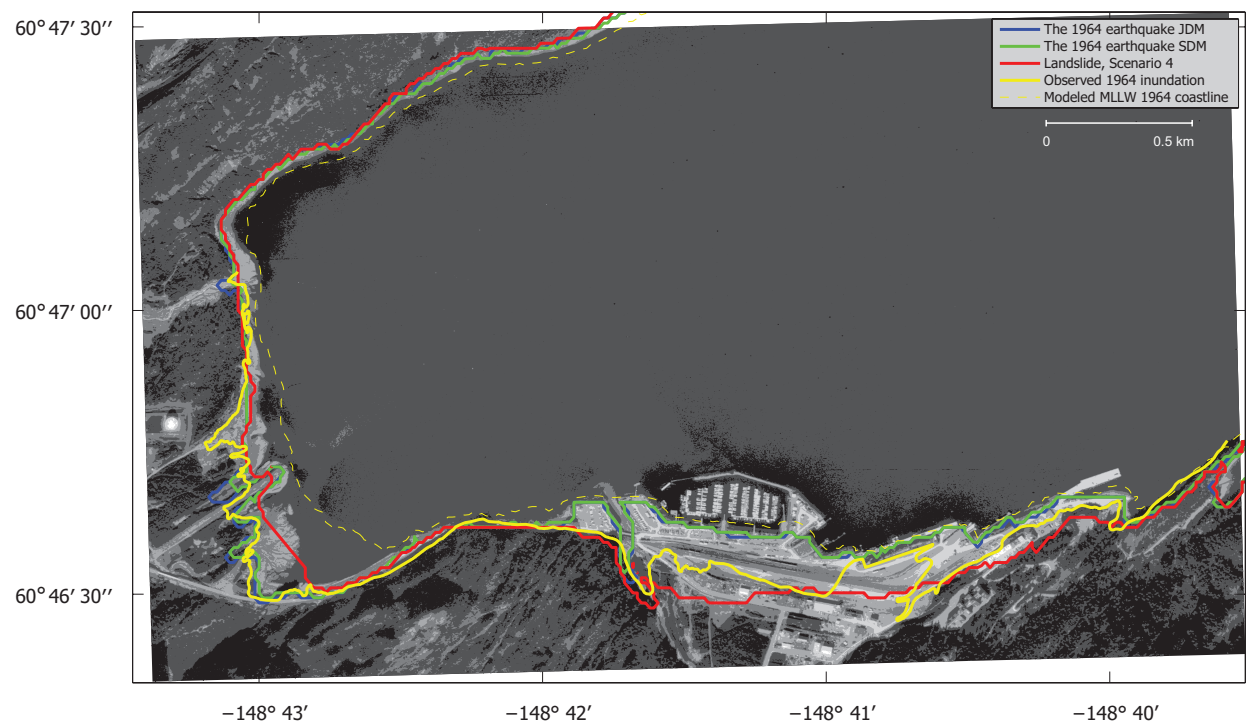

Fig. 13. Observed and modeled 1964 inundation caused by tectonic and landslide-generated waves. The yellow line represents the observed inundation after the 1964 tsunami. The modeled MLLW shoreline before the earthquake is shown by a dashed yellow line. The DEM height corresponds to the pre-earthquake sea level datum.

simulated water level dynamics in the Whittier harbor match each other rather well, as shown in Fig. 12. We conclude that the major tectonic tsunami in Whittier, $60 \mathrm{~min}$ after the earthquake, is primarily determined by the sea level deformation inside Prince William Sound relative to the Gulf of Alaska. Waves triggered by coseismic displacement at the Patton Bay fault arrive later and do not significantly change the wave dynamics. We conclude that the displacement at the Patton Bay fault is not relevant to the tectonic tsunami hazard in Whittier.

The 1964 earthquake occurred at 5:30 pmLT in Whittier when tides were $0.3 \mathrm{~m}$ above the MLLW. We note that the difference between the MHHW and MLLW in Whittier is $3.7 \mathrm{~m}$. Figure 12 shows the simulated water level dynamics in the Whittier harbor and reveals that the maximum wave that hit Whittier was about $3.5 \mathrm{~m}$ (if the local $1.6 \mathrm{~m}$ subsidence is accounted for) at the MLW tide. This wave is within the tidal range for the community and does not produce flooding. This partially explains the reason that the residents of Whittier did not observe the arrival of tectonic waves after the earthquake. The modeled wave action in Passage Canal continues at least for $24 \mathrm{~h}$, but the simulated tectonic tsunami rarely reaches a height above $2 \mathrm{~m}$, and since the harbor parking lot at the elevation of approximately 2 to $3 \mathrm{~m}$ above the MHHW water level is not flooded later during a high tide.

Finally, we show the computed inundations by tsunami waves generated by the JDM, SDM, landslides as well as the observed 1964 inundation zone in Whittier in Fig. 13. The broken yellow line represents the $0 \mathrm{~m}$ elevation with respect to the sea level in Whittier at the time of the earthquake. The modeled inundation by JDM and SDM almost coincide with the shore line, except for low lying areas at the head of Passage Canal. 


\section{Sources of errors and uncertainties}

The hydrodynamic model used to calculate tsunami propagation and runup is a non-linear flux-formulated shallow water model (Nicolsky et al., 2010a). It was verified and validated according to tests for models used in production of tsunami inundation maps (Synolakis et al., 2007).

In a series of papers, several numerical methods, based on Boussinesq-type approximation, were developed (e.g. Madsen et al., 1991; Nwogu, 1993; Wei and Kirby, 1995; Kirby et al., 1998; Lynett and Liu, 2002). However, despite resolving the wave dispersion, the models that utilize the Boussinesq approximation might not have appreciable advantage over classical shallow water methods in matching field observations of runup (Lynett et al., 2003; Synolakis and Bernard, 2006). Moreover, when a tsunami is generated in a steep-walled glacial fjord such as Passage Canal, the effect of wave dispersion on tsunami dynamics can be considered small, because the distance from a landslide location to the shore is probably too small for the waves to disperse (E. Pelinovsky and C. Harbitz, personal communication, 2010). An interested reader can consult (Harbitz et al., 2006) for a discussion of dispersive effects in modeling landslides within glacial fjords. We note that the displacement of the ocean bottom and landslide configuration have the largest uncertainties in tsunami modeling.

While analyzing numerical modeling of the tectonic wave, we assumed that the tectonic tsunami does not interact with ocean tides. The action of the tectonic tsunami lasted through out the entire tidal cycle and could have been amplified by a local bathymetry. For example, the highest wave in Cordova, which is located amidst several islands and shallow areas, arrived at the high tide almost $6-7 \mathrm{~h}$ after the earthquake (Wilson and Tørum, 1968). Since Whittier is connected to Prince William Sound by a deep U-shaped channel, the nonlinear interaction of the tsunami and tides could be assumed small in Passage Canal. An interesting reader is referred to Kowalik et al. (2006); Kowalik and Proshutinsky (2010) for a fruitful discussion of the tsunami-tide interaction.

We finally mention that the resolution of the grid used for inundation modeling is approximately $15 \mathrm{~m}$. This resolution satisfies recommendations by Nation Tsunami Hazard Mitigation Program in US to model tsunami inundation and to describe major relief features. However this scale is limited by the resolution of the topographic and bathymetric data used for the grid construction and cannot be used to model small topographic features including buildings, narrow jetties, etc.

\section{Mitigation of the tsunami hazard}

Although, the 1964 Alaska Tsunami was the most destructive event experienced in the instrumentally recorded history of Alaska, it is believed that the tectonic wave did not cause much damage in Whittier. The earthquake-induced seiche and landslide-generated waves were responsible for the heavy damage to the near-shore infrastructure and the human death toll.

Engineering studies conducted after the 1964 earthquake in Seward, Valdez and Whittier concluded that underwater slope failures have not improved slope stability (Kachadoorian, 1965; Coulter and Migliaccio, 1966; Lemke, 1967), and that the same slopes can fail again during the next large earthquake. Hampton et al. (2002) note that the stability of the sediments can be also decreased by extreme low tides and construction activities in ports and harbors. This makes a landslide-generated tsunami a persistent threat for the city of Whittier.

We note that the 1964 earthquake occurred almost at the MLLW level, otherwise the damage and death toll could have been more severe. Therefore, modeling and understanding of the landslide-generated waves during the 1964 event helps to estimate tsunami inundation at other stages of the ocean tide, and hence to mitigate tsunami hazard in Whittier.

A recent paleoseismic study (Shennan et al., 2009) showed that earthquakes about 1500 and 900 years BP ruptured a larger area than that of the 1964 earthquake. It is possible that the worst-case tsunami scenario for Whittier could exceed the 1964 event, however analysis of such an event is beyond the scope of this article. The analysis of hypothetical tsunamigenic earthquakes affecting the city of Whittier is provided in (Nicolsky et al., 2010b).

\section{Conclusions}

We numerically model a seiche wave, landslide-generated tsunami and tectonic tsunami in Whittier during the 1964 event. Results of our numerical simulation are consistent with most of the eyewitness observations and interpretations by (Kachadoorian, 1965). We show that the city of Whittier was inundated shortly after the beginning of the ground shaking by local waves, triggered by the land displacement and multiple submarine slope failures.

The computed inundation from the simulated seiche wave is primarily located along the shoreline and does not significantly depend on the duration of the displacement. The computed inundations caused by the landslide-generated tsunami closely match the observations within the downtown and depend on the landslide configuration and volume. The thicknesses and distribution of underwater slides are derived from the analysis of data in (Kachadoorian, 1965). We found that landslide complexes at the head and along the northern shore of the canal triggered the major tsunami with 
devastating runup at Whittier. Due to the lack of geotechnical surveys in Passage Canal, it is hard to restrict locations of the northern slide complex. Moreover, while analyzing the tsunami observations, we assumed that the first wave was the seiche. It could be that the first observed wave was triggered by a landslide whose location is not wellestablished. Further geotechnical investigations are required to map Passage Canal and establish previous slide areas. The presented modeling results will be useful for locating potential areas of future geotechnical surveys in Passage Canal.

According to the modeling results, the tectonic tsunami wave arrived at Whittier about an hour after the earthquake. The height of the simulated tectonic tsunami was within the tidal range in Passage Canal. This explains the reason the tectonic wave was unnoticed by local residents.

Finally, we model inundation corresponding to the seiche, and landslide-generated and tectonic tsunamis in Whittier during the 1964 event. The results presented in this article will help to mitigate hazards and prepare this community for a potential future tsunami.

Acknowledgements. We would like to thank R. Grapenthin, M. Nosov, E. Pelinovsky, C. Harbitz, E. Synolakis, R. Combelick, S. Grilli, J. Stroh and others for all their valuable advice, critique and reassurances along the way. We are thankful to reviewers and the editor for valuable suggestions making the manuscript easier to read and understand. This study was supported by NOAA grants 27-014d and 06-028a through Cooperative Institute for Arctic Research. Numerical calculations for this work are supported by a grant of High Performance Computing resources from the Arctic Region Supercomputing Center at the University of Alaska Fairbanks as part of the US Department of Defense HPC Modernization Program.

Edited by: I. Didenkulova

Reviewed by: W. Knight and W. Power

\section{References}

Arakawa, A. and Lamb, V.: Computational design of the basic dynamical processes of the UCLA general circulation model, in: Methods in Computational Physics, Academic Press, 17, 174267, 1977.

Arnold, V.: Mathematical methods of classical mechanics, 2nd edn., Springer, 508 pp., 1989.

Assier-Rzadkiewicz, S., Mariotti, C., and Heinrich, P.: Numerical Simulation of Submarine Landslides and Their Hydraulic Effects, J. Waterw. Port C.-ASCE, 123, 149-157, 1997.

Barberopoulou, A., Qamar, A., Pratt, T., and Steele, W.: Long period effects of the Denali earthquake on water bodies in the Puget Lowland: observations and Modeling, B. Seismol. Soc. Am., 96, 519-535, 2006.

Caldwell, R., Eakins, B., and Lim, E.: Digital Elevation Models of Prince William Sound, Alaska: Procedures, Data Sources and Analysis, National Geophysical Data Center, NOAA, Tech. rep., 43 pp., 2009.
Carver, G. and Plafker, G.: Paloseismicity and neotectonics of the Aleutian subduction zone - an overview, in: Acive tectonics and seismic potential of Alaska, edited by: Freymueller, J., Haeussler, P., Wesson, R., and Ekström, G., Washington, DC, AGU, Geophysical Monograph Series 179 43-63, 2008.

Christensen, D. and Beck, S.: The rupture process and tectonic implications of the great 1964 Prince William Sound earthquake, Pure Appl. Geophys., 142, 29-53, 1994.

Coulter, H. and Migliaccio, R.: Effects of the Earthquake of March 27, 1964, at Valdez, Alaska, US Geol. Surv. Prof. Paper 542-C, 1966.

Dalrymple, R. and Rogers, B.: Numerical modeling of water waves with the SPH method, Coast. Eng., 53, 141-147, 2006.

DeMets, C., Gordon, R., Argus, D., and Stein, S.: Current plate motions, Geophys. J. Int., 101, 425-478, 1990.

Fine, I., Rabinovich, A., Kulikov, E., Thomson, R., and Bornhold, B.: Numerical modelling of landslide-generated tsunamis with application to the Skagway Harbor tsunami of November 3, 1994, in: Proceedings International Conference on Tsunamis, 211-223, Paris, 1998.

Fletcher, C.: Computational Techniques for Fluid Dynamics 1, Springer-Verlag, 401 pp., 1991.

Gardarsson, S.: Shallow water sloshing, Ph.D. thesis, University of Washington, 1997.

George, D. L. and LeVeque, R. J.: Finite Volume Methods and Adaptive Refinement for Global Tsunami Propagation and Inundation, Science of Tsunami Hazards, 24, 319-328, 2006.

Geosystem, L.: GPS User manual, Leica Geosystems AG, Heerbrugg, Switzerland, Tech. rep., 62 pp., 2002.

Grilli, S. and Watts, P.: Tsunami generation by submarine mass failure. I: Modeling, experimental validation, and sensitivity analysis, J. Waterw. Port C. ASCE, 131, 283-297, doi:10.1061/ (ASCE)0733-950X(2005)131:6(283), 2005.

Hampton, M., Lemke, R., and Coulter, H.: Submarine landslides that had a significant impact on man and his activities: Seward and Valdez, Alaska, in: Submarine Landslides: Selected Studies in the US Exclusive Economic Zone, edited by: Schwab, W., Lee, H., and Twichell, D., US Geological Survey Bulletin, 123134, 2002.

Harbitz, C.: Model simulations of tsunamis generated by the Storegga Slides, Mar. Geol., 105, 1-21, 1992.

Harbitz, C., Løvholt, F., Pedersen, G., and Masson, D.: Mechanisms of tsunami generation by submarine landslides: a short review, Norw. J. Geol., 86, 255-264, 2006.

Holdahl, S. and Sauber, J.: Coseismic slip in the 1964 Prince William Sound earthquake: A new geodetic inversion, Pure Appl. Geophys., 142, 55-82, 1994.

Ichinose, G., Somerville, P., Thio, H., Graves, R., and O'Connell, D.: Rupture process of the 1964 Prince William Sound, Alaska, earthquake from the combined inversion of seismic, tsunami, and geodetic data, J. Geophys Res., 112, B07306, doi:10.1029/2006JB004728, 2007.

Imamura, F.: Tsunami numerical simulation with the staggered leap-frog scheme, School Disaster Control Research Center, Tohoku University, Manuscript for TUNAMI code, Tech. rep., 33 pp., 1995.

Imamura, F.: Review of tsunami simulation with a finite difference method, in: Long-Wave Runup Models, edited by: Yeh, H., Liu, P., and Synolakis, C., World Scientific, 25-42, 1996. 
Imamura, F., Hashi, K., and Imteaz, M.: Modeling for tsunamis generated by landsliding and debris flow, in: Tsunami Research at the End of a Critical Decade, edited by: Hebenstreit, G. T., Kluwer, 209-228, 2001.

Iwasaki, S.: Experimental study of a tsunami generated by a horizontal motion of a sloping bottom, University of Tokyo, Bulletin of the Earthquake Research Institute, 239-262, 1982.

Jiang, L. and LeBlond, P.: The coupling of a submarine slide and the surface waves which it generates, J. Geophys. Res., 97, 1273112744, 1992.

Jiang, L. and LeBlond, P.: Three-dimensional modeling of tsunami generation due to a submarine mudslide, J. Phys. Oceanogr., 24, 559-572, 1994.

Johnson, J., Satake, K., Holdahl, S. R., and Sauber, J.: The 1964 Prince William Sound earthquake: Joint inversion of tsunami and geodetic data, J. Geophys. Res., 101, 523-532, 1996.

Kachadoorian, R.: Effects of the earthquake of March 27, 1964, at Whittier, Alaska, US Geol. Surv. Prof. Paper 542-B, B1-B21, 3 sheets, scale 1:4800, 1965.

Kirby, J., Wei, G., Chen, Q., Kennedy, A., and Dalrymple, R.: FUNWAVE 1.0, fully nonlinear boussinesq wave model documentation and users manual, Center for Applied Coastal Research, University of Delaware, Tech. Rep. Research Report No. CACR-98-06, 1998.

Kowalik, Z. and Murty, T.: Numerical modeling of ocean dynamics, World Scientific, 481 pp., 1993a.

Kowalik, Z. and Murty, T.: Numerical simulation of twodimensional tsunami runup, Mar. Geod., 16, 87-100, 1993b.

Kowalik, Z. and Proshutinsky, A.: Tsunami tide interactions: A Cook Inlet case study, Cont. Shelf Res., 30, 633-642, 2010.

Kowalik, Z., Proshutinsky, T., and Proshutinsky, A.: Tide-Tsunami Interactions, Science of Tsunami Hazards, 24, 242-256, 2006.

Kvale, A.: Seismic seiches in Norway and England during the Assam earthquake of August 15, 1950, B. Seismol. Soc. Am., 45, 93-113, 1953.

Lamb, H.: Hydrodynamics, 4th edn., Cambridge, University Press, 708 pp., 1916.

Lemke, R.: Effects of the earthquake of March 27, 1964, at Seward, Alaska, US Geol. Surv. Prof. Paper 542-E, 48 pp., 1967.

Levin, B. and Nosov, M.: Physics of Tsunamis, Springer, 327 pp., 2008.

Lim, E., Eakins, B., and Wigley, R.: Southern Alaska Coastal Relief Model: Procedures, Data Sources and Analysis, National Geophysical Data Center, NOAA, Boulder, Colorado, Tech. rep., 25 pp., 2009.

Liu, P. L.-F., Woo, S., and Cho, Y.: Computer Programs for Tsunami Propagation and Inundation, Tech. rep., Cornell University, 104 pp., 1998.

Liu, P. L.-F., Synolakis, C., and Yeh, H.: Report on the International Workshop on Long-Wave Runup, J. Fluid Mech., 229, 675-688, 1991.

Lynett, P. and Liu, P. L.-F.: A Numerical Study of Submarine Landslide Generated Waves and Runup, P. Roy. Soc. A, 458, 2885-2910, 2002.

Lynett, P. and Liu, P. L.-F.: A two-layer approach to water wave modeling, P. Roy. Soc. A, 460, 2637-2669, 2004a.

Lynett, P. and Liu, P. L.-F.: Linear analysis of the multi-layer model, Coast. Eng., 51, 439-454, 2004 b.

Lynett, P. and Liu, P. L.-F.: A Numerical Study of the Runup
Generated by Three-Dimensional Landslides, J. Geophys. Res., 110, 1-16, doi:10.1029/2004JC002443, 2005.

Lynett, P., Borrero, J., Liu, P. L.-F., and Synolakis, C.: Field survey and numerical simulations: a review of the 1998 Papua New Guinea earthquake and tsunami, Pure Appl. Geophys., 160, 2119-2146, 2003.

Mader, C. and Lukas, S.: SWAN-A Shallow Water, Long Wave Code, Hawaii Institute of Geophysics, University of Hawaii, Tech. Rep. HIG-84-4, 1984.

Madsen, P., Murray, R., and Sorensen, O.: A new form of the Boussinesq equations with improved linear dispersion characteristics, Coast. Eng., 15, 371-388, 1991.

McGarr, A.: Excitation of seiches in channels by seismic waves, J. Geophys. Res., 70, 847-854, 1965.

Merian, J.: Über die Bewegung tropbarer Flussigkeiten in Gefassen, Basle, 646 pp., 1828 (in German).

Miyoshi, H.: Generation of the tsunami in compressible water (Part I), Journal of the Oceanographical Society of Japan, 10, $1-9,1954$.

Nicolsky, D., Suleimani, E., and Hansen, R.: Validation and verification of a numerical model for tsunami propagation and runup, Pure Appl. Geophys., in press, doi:10.1007/s00024-0100231-9, 2010a.

Nicolsky, D., Suleimani, E., Combellick, R., and Hansen, R.: Tsunami Hazard Maps of Whittier and western Passage Canal, Alaska, US Geol. Surv. Prof. Paper, submitted, 2010b.

Nishenko, S. and Jacob, K.: Seismic potential of the Queen Charlotte-Alaska-Aleutian seismic zone, J. Geophys. Res., 95, 2511-2532, 1990.

Nosov, M. A. and Kolesov, S. V.: Elastic oscillations of water column in the 2003 Tokachi-oki tsunami source: in-situ measurements and 3-D numerical modelling, Nat. Hazards Earth Syst. Sci., 7, 243-249, doi:10.5194/nhess-7-243-2007, 2007.

Nwogu, O.: Alternative form of Boussinesq equations for nearshore wave propagation, J. Waterw. Port C.-ASCE, 119, 618-638, 1993.

Olsen, K. and Archuleta, R.: Three-Dimensional simulation of earthquakes on the Los Angeles fault system, B. Seismol. Soc. Am., 86, 575-596, 1996.

Page, R., Biswas, N., Lahr, J., and Pulpan, H.: Seismicity of continental Alaska, in: Neotectonics of North America, edited by: Slemmons, D., Engdahl, E., Zoback, M., and Blackwell, D., Geological Society of America, Boulder, Colorado, Decade Map, 1, 47-68, 1991.

Plafker, G.: Tectonic Deformation Associated with the 1964 Alaska Earthquake, Science, 148, 1675-1687, 1965.

Plafker, G., Kachadoorian, R., Eckel, E., and Mayo, L.: Effects of the Earthquake of March 27, 1964 on various communities, US Geol. Surv. Prof. Paper 542-G, 1969.

Proudman, J.: Dynamical Oceanography, Methuen, London, 409 pp., 1953.

Rabinovich, A. B., Thomson, R. E., Bornhold, B. D., Fine, I. V., and Kulikov, E. A.: Numerical Modelling of Tsunamis Generated by Hypothetical Landslides in the Strait of Georgia, British Columbia, Pure Appl. Geophys., 160, 1273-1313, 2003.

Santini, S., Dragoni, M., and Spada, G.: Asperity distribution of the 1964 Great Alaska earthquake and its relation to subsequent seismicity in the region, Tectonophysics, 367, 219-233, doi:10. 1016/S0040-1951(03)00130-6, 2003. 
Shannon, W. and Hilts, D.: Submarine landslide at Seward, in: The Great Alaska Earthquake of 1964, National Academy of Sciences, Washington, DC, USA, Engineering, Engineering Volume, 144-156 pp., 1973.

Shennan, I., Bruhn, R., and Plafker, G.: Multi-segment earthquakes and tsunami potential of the Aleutian megathrust, Quaternary Sci. Rev., 28, 7-13, 2009.

Shuto, N.: Tsunami Hazard, chap. Numerical simulation of tsunamis, Kluwer Academic Publishers, Netherlands, 171191 pp., 1991.

Suito, H. and Freymueller, J.: A viscoelastic and afterslip postseismic deformation model for the 1964 Alaska earthquake, J. Geophys. Res., 114, doi:10.1029/2008JB005954, 2009.

Suleimani, E., Hansen, R., and Haeussler, P.: Numerical study of tsunami generated by multiple submarine slope failures in Resurrection Bay, Alaska, during the $M_{w} 9.21964$ earthquake, Pure Appl. Geophys., 166, 131-152, doi:10.1007/s00024-0040430-3, 2009.

Suleimani, E., Nicolsky, D., Haeussler, P., and Hansen, R.: Combined effects of tectonic and landslide-generated tsunami runup at Seward, Alaska during the $M_{w} 9.21964$ earthquake, Pure Appl. Geophys., in press, doi:10.1007/s00024-010-0228-4, 2010.

Synolakis, C.: The Runup of Long Waves, Ph.D. thesis, California Institute of Technology, Pasadena, California, 228 pp., 1986.

Synolakis, C.: Earthquake Engineering Handbook, in: Tsunamis and seiches, CRC Press, Boca Raton, Florida, 2003.

Synolakis, C. and Bernard, E.: Tsunami science before and beyond Boxing Day 2004, Philos. T. Roy. Soc. A, 364, 2231-2265, 2006.

Synolakis, C., Bernard, E., Titov, V., Kânoğlu, U., and González, F.: Standards, criteria, and procedures for NOAA evaluation of tsunami numerical models, NOAA/OAR/PMEL, Seattle, Washington, OAR PMEL-135 Special Report, 55 pp., 2007.
Tanioka, Y. and Satake, K.: Tsunami generation by horizontal displacement of ocean bottom, Geophys. Res. Lett., 23, 861-864, 1996.

Thomson, R., Rabinovich, A., Kulikov, E., Fine, I., and Bornhold, B.: On numerical simulation of the landslide-generated tsunami of November 3, 1994 in Skagway Harbor, Alaska, in: Tsunami Research at the End of a Critical Decade, edited by: Hebenstreit, G. T., Kluwer, 243-282 pp., 2001.

Titov, V. and Gonzalez, F.: Numerical study of the source of the July 17, 1998 PNG tsunami, in: Tsunami Research at the End of a Critical Decade, edited by: Hebenstreit, G. T., Kluwer, 197207 pp., 2001.

Titov, V. and Synolakis, C.: Evolution and Runup of Breaking and Nonbreaking waves using VTSC2, J. Waterw. Port C.-ASCE, 121, 308-316, 1995.

Titov, V. and Synolakis, C.: Numerical modeling of tidal wave runup, J. Waterw. Port C.-ASCE, 124, 157-171, 1998.

Wei, G. and Kirby, J.: A time-dependent numerical code for extended Boussinesq equations, J. Waterw. Port C.-ASCE, 120, 251-261, 1995.

Wilson, B. and Tørum, A.: The tsunami of the Alaskan Earthquake, 1964: Engineering evaluation, U.S. Army Corps of Engineers, Technical memorandum No. 25, 401 pp., 1968.

Yeh, H., Liu, P. L.-F., Briggs, M., and Synolakis, C. E.: Propagation and amplification of tsunamis at coastal boundaries, Nature, 372, 353-355, 1994.

Zhang, Y. and Baptista, A.: An Efficient and Robust Tsunami Model on Unstructured Grids. Part I: Inundation Benchmarks, Pure Appl. Geophys., 165, 2229-2248, 2008. 